\title{
Headache and mechanical sensitization of human pericranial muscles after repeated intake of monosodium glutamate (MSG)
}

\author{
Akiko Shimada ${ }^{1 *}$, Brian E Cairns ${ }^{2}$, Nynne Vad ${ }^{1}$, Kathrine Ulriksen ${ }^{1}$, Anne Marie Lynge Pedersen ${ }^{3}$, \\ Peter Svensson ${ }^{1,4}$ and Lene Baad-Hansen ${ }^{1}$
}

\begin{abstract}
Background: A single intake of monosodium glutamate (MSG) may cause headache and increased muscle sensitivity. We conducted a double-blinded, placebo-controlled, crossover study to examine the effect of repeated MSG intake on spontaneous pain, mechanical sensitivity of masticatory muscles, side effects, and blood pressure.

Methods: Fourteen healthy subjects participated in 5 daily sessions for one week of MSG intake $(150 \mathrm{mg} / \mathrm{kg})$ or placebo (24 mg/kg NaCl) (randomized, double-blinded). Spontaneous pain, pressure pain thresholds and tolerance levels for the masseter and temporalis muscles, side effects, and blood pressure were evaluated before and 15, 30, and 50 min after MSG intake. Whole saliva samples were taken before and 30 min after MSG intake to assess glutamate concentrations.

Results: Headache occurred in $8 / 14$ subjects during MSG and 2/14 during placebo ( $P=0.041$ ). Salivary glutamate concentrations on Day 5 were elevated significantly $(P<0.05)$. Pressure pain thresholds in masseter muscle were reduced by MSG on Day 2 and $5(P<0.05)$. Blood pressure was significantly elevated after MSG $(P<0.040)$.

Conclusion: In conclusion, MSG induced mechanical sensitization in masseter muscle and adverse effects such as headache and short-lasting blood pressure elevation for which tolerance did not develop over 5 days of MSG intake.
\end{abstract}

Keywords: Monosodium glutamate, Craniofacial sensitivity, Pain, Accumulation, Headache

\section{Background}

Temporomandibular Disorders (TMD) affect approximately $10 \%$ of the population [1,2]. The principal symptom of TMD that most often leads patients to seek medical treatment is pain in the temporomandibular joint and/or masticatory muscles [1]. Around $70 \%$ of TMD patients report masticatory muscle pain and are described as suffering from myofascial TMD [3]. In the majority of myofascial TMD cases, there is little evidence of ongoing pathological change in masticatory muscles, and, consequently, a number of alternative mechanisms have been proposed to explain pathogenesis of this pain $[1,3]$. Of

\footnotetext{
* Correspondence: akiko.shimada@odontologi.au.dk

'Section of Clinical Oral Physiology, Department of Dentistry, Faculty of Health Sciences, Aarhus University, Vennelyst Boulevard 9, Aarhus C 8000, Denmark

Full list of author information is available at the end of the article
}

these potential mechanisms, life-style related factors may play an important role in development and maintenance of muscle pain in myofascial TMD. For example, chronic stress has been speculated to lead to parafunctional activities such as repetitive tooth clenching or grinding that then produces strain injury to masticatory muscles leading to pain [4-6], although the relationship between bruxism and craniofacial pain may be more complex $[7,8]$. Diet may be another important life-style related factor contributing the muscle pain in myofascial TMD, as it has been reported that TMD patients alter their diet to avoid exacerbating pain associated with mastication of certain foods [9]. However, very little is currently known about the interaction between food intake and pain in TMD.

Consumption of certain foods is thought to precipitate or aggravate other chronic craniofacial pain conditions. One postulated food trigger for migraine headaches is 
monosodium glutamate (MSG), which is used as a taste enhancer in many snack and fast foods [10]. Indeed, total dietary consumption of glutamate ranges from 50$200 \mathrm{mg} / \mathrm{kg} /$ day $[11,12]$. Of note, healthy young men who consumed a single dose of $150 \mathrm{mg} / \mathrm{kg}$ MSG had a significant increase in headache and craniofacial muscle sensitivity as well as an elevated systolic blood pressure [13], suggesting that MSG consumption may trigger more types of craniofacial pain than just headaches. A significant amount of systemically administered glutamate is known to be taken up by skeletal muscles, including the masticatory muscles [14]. The resulting elevation of interstitial glutamate concentration sensitizes muscle nociceptors to mechanical stimuli [15]; an effect which could underlie reports of craniofacial muscle pain sensitivity in healthy young men given MSG [13]. Further, there is evidence that glutamate concentrations are elevated in painful regions of masticatory muscles of myofascial TMD patients compared to healthy controls [16].

Although a single $150 \mathrm{mg} / \mathrm{kg}$ dose of MSG did result in a demonstrable increase in craniofacial sensitivity in young healthy men, more regular consumption of this quantity of MSG may result in tolerance to the acute sensitizing effects of MSG [13]. On the other hand, chronic daily administration of $150 \mathrm{mg} / \mathrm{kg}$ of MSG might lead to the accumulation of MSG in masticatory muscles, which might be manifested by enhanced craniofacial sensitivity reminiscent of symptoms reported by myofascial TMD patients. The current study was therefore conducted to assess the impact of 5 days of consumption of $150 \mathrm{mg} / \mathrm{kg}$ MSG on craniofacial pain sensitivity in healthy subjects.

\section{Methods}

\section{Study design and subjects}

This study was performed as a double-blinded, placebocontrolled cross-over trial. The study protocol was approved by the local ethics committee (approval No. 20060040 - amendment No. 2 of March 2010) and informed consent was obtained from all subjects. The study was conducted in accordance with the Declaration of Helsinki. Randomization was performed by a computer and the examiners were blinded until after finishing data collection on all subjects.

Fourteen healthy adult ( $>18$ years) subjects ( 9 women and 5 men, mean age $27.6 \pm 1.7$ years, mean bodyweight $64.1 \pm 2.5 \mathrm{~kg}$ ) were included in the study through the webpage (www.forsoegsperson.dk) and among staffs and students at the Department of Dentistry, Aarhus University. Exclusion criteria were: orofacial pain, chronic illness, e.g. uncontrolled hypertension, allergy to MSG, asthma, diabetes mellitus, body mass index > 25 [13].

Each subject participated in $10(2 \times 5)$ sessions (Monday through Friday in two consecutive weeks). In one week, the subjects received MSG, and in the other week, placebo (see below), in randomized order.

\section{Baseline measurements}

On the first day, the bodyweight of the subject was measured with the use of a digital scale. The subjects were asked to fast for at least 3 hours before each session. In each of the 10 sessions at baseline (BL), after a 10 min rest, a resting whole saliva sample was collected using the draining method [17]. The collection of saliva samples took place in a quiet room. The subjects were seated upright in a chair with the head slightly bent forward, and instructed to drool into a plastic cup for $10 \mathrm{~min}$ [18]. The subjects were then asked to rate spontaneous pain (if any) on a 010 numerical rating scale (NRS, $0=$ no pain, $10=$ most imaginable pain). Then, pressure pain thresholds (PPT) and pressure pain tolerance levels (PPTol) of the left masseter and temporalis muscles were measured [19]. Systolic and diastolic blood pressure $(\mathrm{BP})$ and heart rate $(\mathrm{HR})$ were also measured with the use of a digital blood pressure monitor (UA-767plus; A\&D Medical, Abingdon, UK).

\section{Administration of monosodium glutamate (MSG) or placebo}

In each session of the MSG week, a drink was prepared of $400 \mathrm{ml}$ sugar-free lemon soda (Spirit light ${ }^{\circledR}$, Coop) by a research assistant in a separate room. The beverage contained carbon dioxide, citric acid, sodium citrate, aromas, artificial sweeteners (aspartame, acesulfame potassium) and sodium benzoate. MSG (150 mg MSG per $\mathrm{kg}$ bodyweight) was added to the soda. In the placebo week, $24 \mathrm{mg}$ per $\mathrm{kg}$ bodyweight of $\mathrm{NaCl}$ was added to the drink instead of MSG to create a similar taste. The drink was ingested over a few min [13].

\section{Pressure pain thresholds and pressure pain tolerance thresholds}

An algometer (Somedic, Hörby, Sweden) was use to assess PPT and PPTol in the masseter and temporalis muscles. To undertake these measurements, the subject's head was gently supported by the opposite hand of the examiner and the subject was instructed to keep his/her teeth slightly apart during the measurements [3,19]. Subjects were instructed to press a button when the force applied by the examiner just became painful (PPT) or when they could no longer tolerate the force being applied (PPTol). PPT (triplicates) and PPTol (single measures) for left masseter and left temporalis were repeated in all sessions 15, 30, and 50 min after drinking the beverage. Only the left side was assessed, since it has been shown that there are no overall differences between sides regarding pressure sensitivity [13]. 


\section{Self-reported pain and adverse effects}

The subjects were asked to rate any pain on a 0-10 NRS at time-points 15, 30 and 50 min after the drink. In addition, they were asked about the following adverse effects: Headache, nausea, dizziness, feeling of chest pressure, burning sensation of skin, tiredness, sore jaw, stomach ache, and "other, please specify" [11,13]. They answered "yes" or "no" to each adverse reaction.

\section{Measurement of glutamate levels in resting whole saliva}

Two resting saliva samples were collected in each session; one prior to and another 30 min after drinking the beverage. The whole saliva samples were pipetted into test tubes and placed on ice immediately after collection and then kept in a freezer $\left(-80^{\circ} \mathrm{C}\right)$ until analysis. Each sample was centrifuged before measurements of glutamate $(1500 \mathrm{~g}$ for $5 \mathrm{~min}$ ). The concentration of glutamate in the whole saliva samples was determined with a commercially available kit (L-Glutaminsäure/L-Glutamate, Thermo Fisher Scientific Inc., Australia) using the photometric analyzer Konelab 30i (Thermo Clinical Labsystems/ILS Laboratories Scandinavia, Denmark). The molecular weight of glutamate is $146 \mathrm{~g} / \mathrm{mol}$. The standard (calibrator) in the kit was $0.1 \mathrm{~g} / \mathrm{L}$ corresponding to $684.9 \mu \mathrm{M}$. Upper test limits for the kit was $3592.00 \mu \mathrm{M}$. A sample volume of $10 \mu \mathrm{L}$ of saliva per measurement was used. Duplicate measurements were performed for each sample at a wavelength of $492 \mathrm{~nm}$. Values of salivary glutamate were given in $\mu \mathrm{M}$.

\section{Blood pressure and heart rate}

$\mathrm{BP}$ and HR measurements with a digital blood pressure monitor (UA-767puls; A\&D Medical, Abingdon, UK) were repeated in all sessions at 15,30 , and $50 \mathrm{~min}$ after drinking the beverage.

\section{Statistics}

All data are presented as means \pm standard error of the mean (SEM). Levels of $P$ less than 0.05 were considered statistically significant. Spontaneous pain, PPT, PPTol, $\mathrm{BP}, \mathrm{HR}$, and glutamate concentration were analyzed with 3-way repeated measurement (RM) analyses of variance (ANOVAs) with intervention (MSG vs. placebo), day (Day 1-5 in each week) and time (BL, 15, 30, $50 \mathrm{~min}$ ) as factors. For glutamate concentration only two time periods (BL and $30 \mathrm{~min}$ ) were used. When appropriate, post hoc Tukey Honestly Significant Difference (HSD) tests with corrections for multiple comparisons were performed. Occurrence of side effects was compared between weeks with McNemar's test.

\section{Results}

\section{Spontaneous pain}

Three subjects experienced spontaneous pain in the craniofacial region in the MSG week (maximum pain level 6,
3 and 2, respectively) and one subject experienced pain (only on Day 1, maximum pain level 3 ) in the placebo week. However, group mean pain scores were low and not significantly influenced by intervention (MSG vs. Placebo), day (Day 1-5), or time (BL, 15, 30, 50 min after intake) $(\mathrm{P}>0.174)$ (Figure 1).

\section{Pressure pain thresholds (PPT) and pressure pain tolerance (PPTol)}

PPT and PPTol measures were normalized to the BL value on Day 1 before analyses. There was no main effect of intervention (MSG vs. placebo) on PPT in left masseter $(\mathrm{P}=0.159, \mathrm{~F}=2.281)$. There was a main effect of day $(\mathrm{P}=$ $0.002, \mathrm{~F}=4.996)$ and time $(\mathrm{P}=0.007, \mathrm{~F}=4.867)$ and $\mathrm{a}$ tendency towards a significant interaction between intervention and day $(\mathrm{P}=0.079, \mathrm{~F}=2.249)$. Post hoc tests revealed that left masseter PPT was significantly reduced on Day 2 and 3 compared to Day 1 ( $<<0.048$; Figure 2). Within sessions, left masseter PPT was increased at the 30 and 50 min time-points compared to $\mathrm{BL}(\mathrm{P}<0.032$; Data not shown). Post hoc analysis of the interaction between intervention and day showed a significant reduction in normalized left masseter PPT on Day 2 and 5 in the MSG week compared to placebo and Day 1 ( $\mathrm{P}<0.029)$ (Figure 2). Left temporalis PPT was not influenced by intervention $(\mathrm{P}=0.411, \mathrm{~F}=0.729)$ or day $(\mathrm{P}=0.337, \mathrm{~F}=$ 1.169) but there was a main effect of time $(P=0.002, F=$ 6.388) (Figure 2). Post hoc tests revealed that left temporalis PPT was increased at 15, 30 and 50 min compared with $\mathrm{BL}$ within sessions $(\mathrm{P}<0.023$; Data not shown).

There was no main effect of intervention $(\mathrm{P}=0.645, \mathrm{~F}=$ $0.225)$ or time $(\mathrm{P}=0.254, \mathrm{~F}=1.420)$ on left masseter PPTol, but there was a main effect of day $(\mathrm{P}=0.026, \mathrm{~F}=$ 3.054). The post hoc test showed a significant decrease in

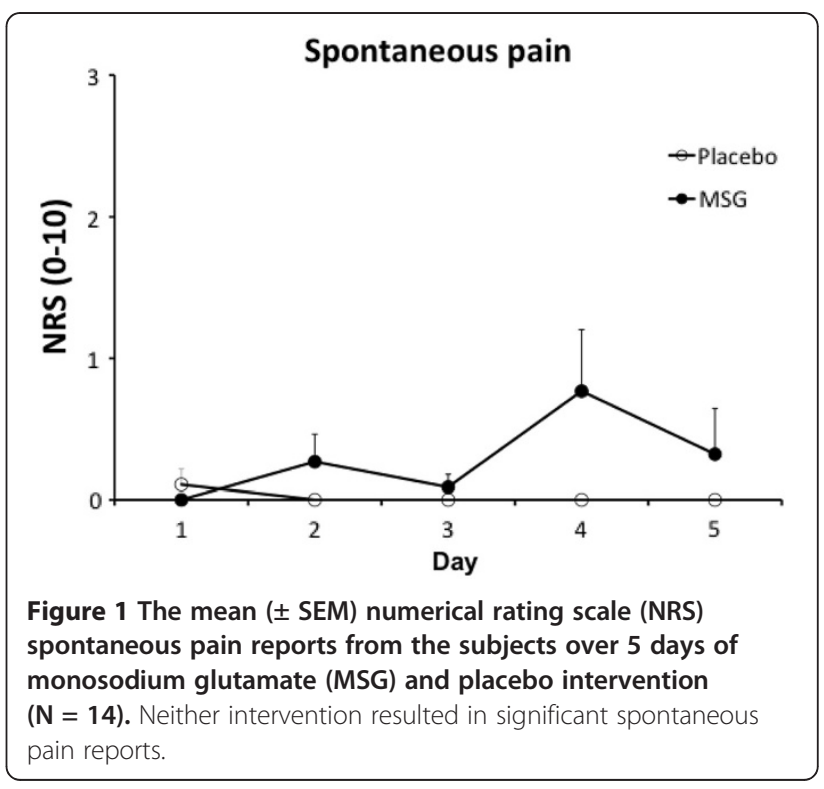



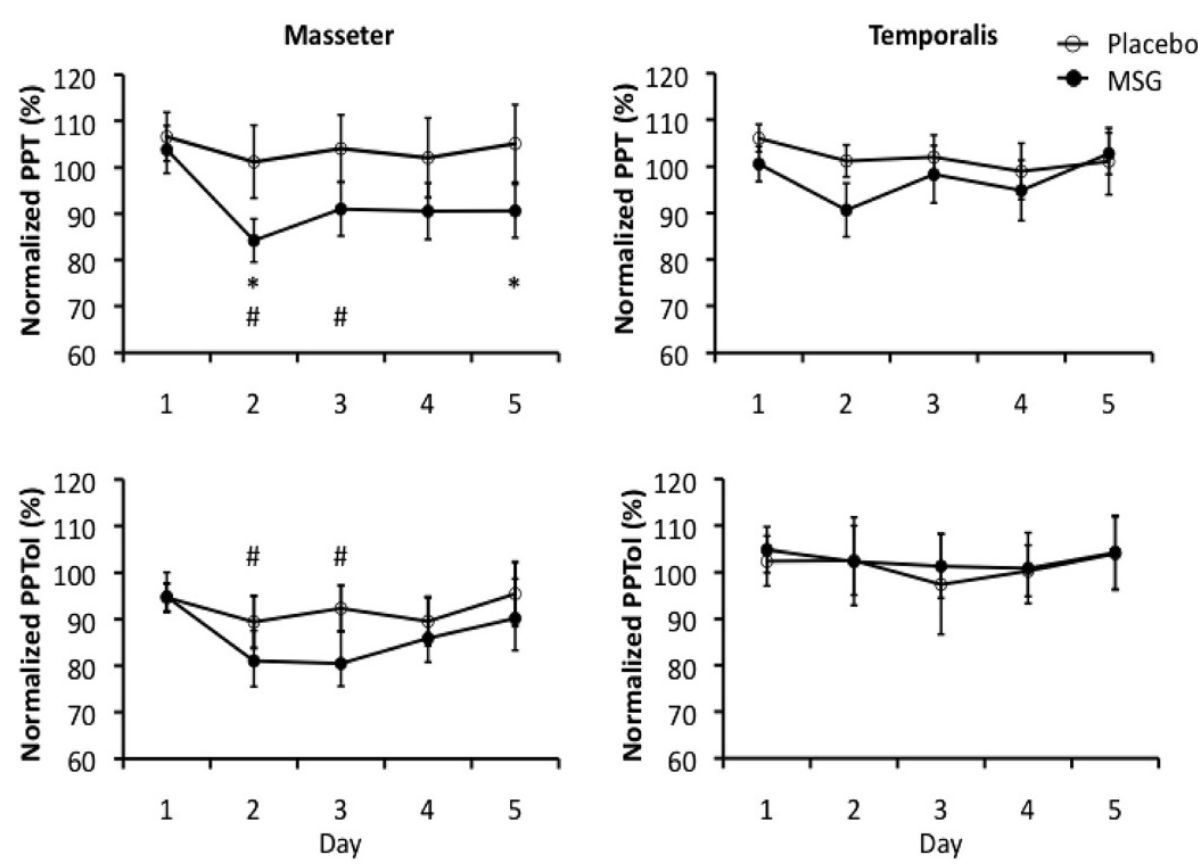

Figure 2 The overall $( \pm$ SEM) mean relative Pressure Pain Threshold (PPT) or Pressure Pain Tolerance (PPTol) for each day (N = 14). There was a trend in PPT values in both muscles and PPTol values in the temporalis muscle to increase due to repeated measurement during each daily session, which resulted in mean overall values that exceeded $100 \%$ on all 5 days during placebo intervention. The masseter muscle PPT and PPTol measured on Day 2 and 3 were both significantly decreased compared to Day 1 (\#: P $<0.05$ ), but this difference occurred independent of intervention. The masseter muscle PPT was, however, significantly lower after monosodium glutamate (MSG) ingestion than after placebo ingestion on Day 2 and 5 (*: P $<0.05)$. There was no effect of intervention or day on the PPT and PPTol measured from the temporalis muscle.

left masseter PPTol on Day 2 and 3 compared to Day 1 $(\mathrm{P}<0.047)$ (Figure 2$)$. Left temporalis PPTol was not significantly influenced by intervention $(\mathrm{P}=0.943, \mathrm{~F}=0.005)$ or day $(\mathrm{P}=0.700, \mathrm{~F}=0.550)$ but there was a main effect of time ( $\mathrm{P}=0.038, \mathrm{~F}=3.156$ ) (Figure 2). Left temporalis PPTol was significantly increased at $50 \mathrm{~min}$ compared with $\mathrm{BL}(\mathrm{P}=0.044$; Data not shown).

\section{Adverse effects}

A greater number of subjects reported adverse effects in the MSG week than in the placebo week (Table 1). The number of subjects who reported headache was significantly higher during the MSG week than during the placebo week. The daily incidence of the various side effects is shown in Figure 3. As can been seen in Figure 3, most side effects were more frequent at the beginning of intervention and tended to be less commonly reported in the final 2 days of MSG intervention. In contrast, some side effects, notably headache and stomach ache, had a similar frequency of occurrence throughout the entire 5 days MSG intervention.

\section{Glutamate levels in whole saliva}

Average trough (daily baseline) levels of salivary glutamate were $17 \pm 3 \mu \mathrm{M}$ in during the 5 days of MSG and
$24 \pm 4 \mu \mathrm{M}$ during the 5 days of placebo. Average peak levels of salivary glutamate were $220 \pm 61 \mu \mathrm{M}$ in MSG week and $14 \pm 2 \mu \mathrm{M}$ in placebo week. The ANOVA of glutamate concentration demonstrated a significant interaction between intervention and day $(\mathrm{P}=0.028, \mathrm{~F}=$ 3.010). Post hoc analyses showed that glutamate levels were significantly higher on Day 2 through Day 5 in the MSG week compared with the placebo week $(P<0.05)$.

Table 1 The percentage of subjects reporting side effects at least once over the 5 days of intervention

\begin{tabular}{lrrr}
\hline Side effect & MSG & Placebo & McNemar's test \\
\hline Nausea & 57.1 & 21.4 & $\mathrm{P}=0.182$ \\
Headache* & $\mathbf{5 7 . 1}$ & $\mathbf{7 . 1}$ & $\mathbf{P}=\mathbf{0 . 0 4 1}$ \\
Dizziness & 35.7 & 0.0 & $\mathrm{P}=0.074$ \\
Chest Pressure & 28.6 & 0.0 & $\mathrm{P}=0.134$ \\
Burning & 21.4 & 7.1 & $\mathrm{P}=0.617$ \\
Fatigue & 50.0 & 28.6 & $\mathrm{P}=0.074$ \\
Sore Jaw & 57.1 & 35.7 & $\mathrm{P}=0.450$ \\
Stomachache & 35.7 & 7.1 & $\mathrm{P}=0.134$ \\
Other* & $\mathbf{5 7 . 1}$ & $\mathbf{1 4 . 3}$ & $\mathbf{P}=\mathbf{0 . 0 2 3}$
\end{tabular}

Other included reports of numbness in appendages, feeling cold, and heartburn. 


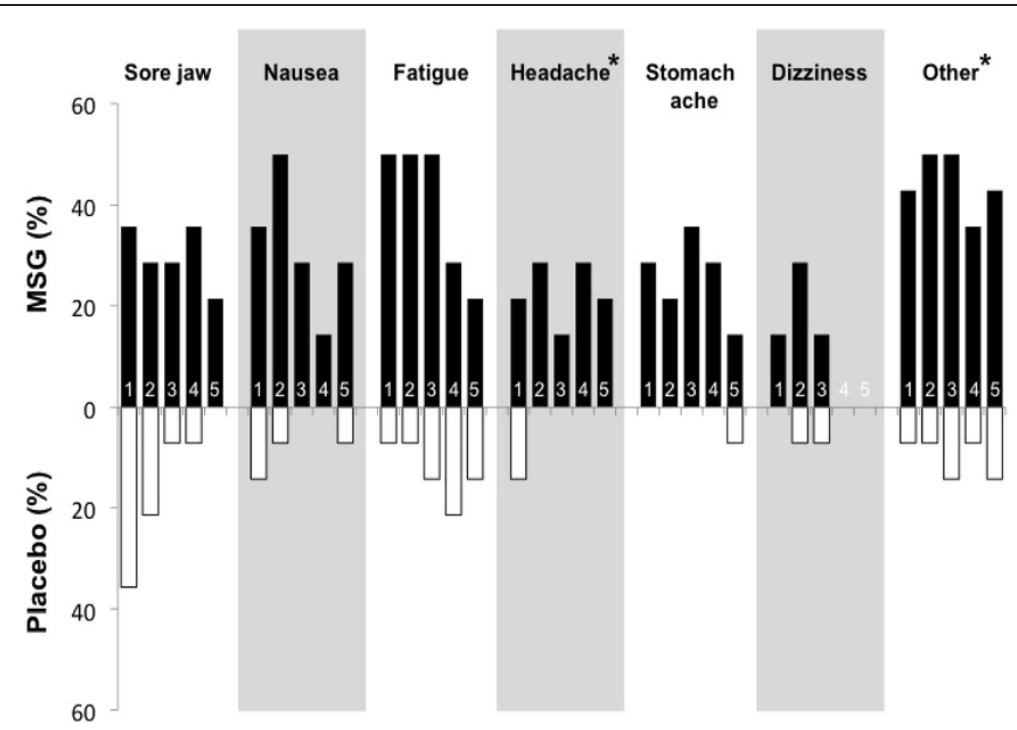

Figure 3 The vertical bar chart shows the frequency of side effects reports by $>30 \%$ of the subjects over 5 days of monosodium glutamate (MSG) (black) and 5 days of placebo (white) intervention. For most side effects, such as nausea and fatigue, there was a peak in reports on the second or third day of administration followed by a gradual decline in reports. There were substantially fewer reports of side effects in the placebo group, with the exception of reports of jaw soreness, which peaked during the first session and then declined. The Occurrence of headache and other side effects showed a significant difference between the interventions by McNemar's test (*: P<0.05).

Also, in the MSG week, glutamate level on Day 5 was significantly higher than that on Day $1(\mathrm{P}<0.05)$ (Figure 4$)$.

\section{Blood pressure (systolic: sBP: diastolic: dBP) and heart rate (HR)}

There were no main effects of intervention $(\mathrm{P}=0.079$, $\mathrm{F}=3.727)$ or day $(\mathrm{P}=0.324, \mathrm{~F}=1.200)$ on sBP. However, there was a main effect of time $(\mathrm{P}=0.026, \mathrm{~F}=3.518)$ and a significant interaction between intervention and time $(\mathrm{P}=0.007, \mathrm{~F}=4.811)$. The post hoc test of the main time effect showed that sBP was elevated $15 \mathrm{~min}$ after intake ( $\mathrm{P}=0.022)$. A post hoc test of the intervention $\times$ time interaction revealed that in the MSG sessions $(\mathrm{P}<0.040)$ but not in placebo sessions $(\mathrm{P}>0.900)$, $\mathrm{sBP}$ was elevated 15 and $30 \mathrm{~min}$ after intake (Figure 5).

There were no main effects on $\mathrm{dBP}$ of intervention $(\mathrm{P}=0.067, \mathrm{~F}=4.132)$, day $(\mathrm{P}=0.602, \mathrm{~F}=0.692)$, or time $(\mathrm{P}=0.099, \mathrm{~F}=2.270)$. However, there was a significant interaction between intervention and time $(P=0.005$, $F=5.049$ ). The post hoc test indicated that $d B P$ was significantly elevated in the MSG sessions at 15 and 30 min after intake compared with placebo sessions $(\mathrm{P}<$ 0.043) (Figure 5).

There were no main effects of intervention $(\mathrm{P}=0.412$, $\mathrm{F}=0.728)$ or day $(\mathrm{P}=0.265, \mathrm{~F}=1.356)$ on $\mathrm{HR}$, but there was a significant effect of time $(\mathrm{P}<0.001, \mathrm{~F}=10.104)$. HR decreased over time and was significantly lower than $\mathrm{BL}$ at 15,30 and $50 \mathrm{~min}$ after intake of either substance $(\mathrm{P}<0.003)$.

\section{Result of blinding procedure}

At the end of each 5 days session, subjects were asked to indicate which substance they thought they had received. Subjects correctly identified the substance given to them $88 \%$ of the time, suggesting that due to the increased number of side effects experienced by many subjects who received MSG, most subjects were able to guess what they were receiving.

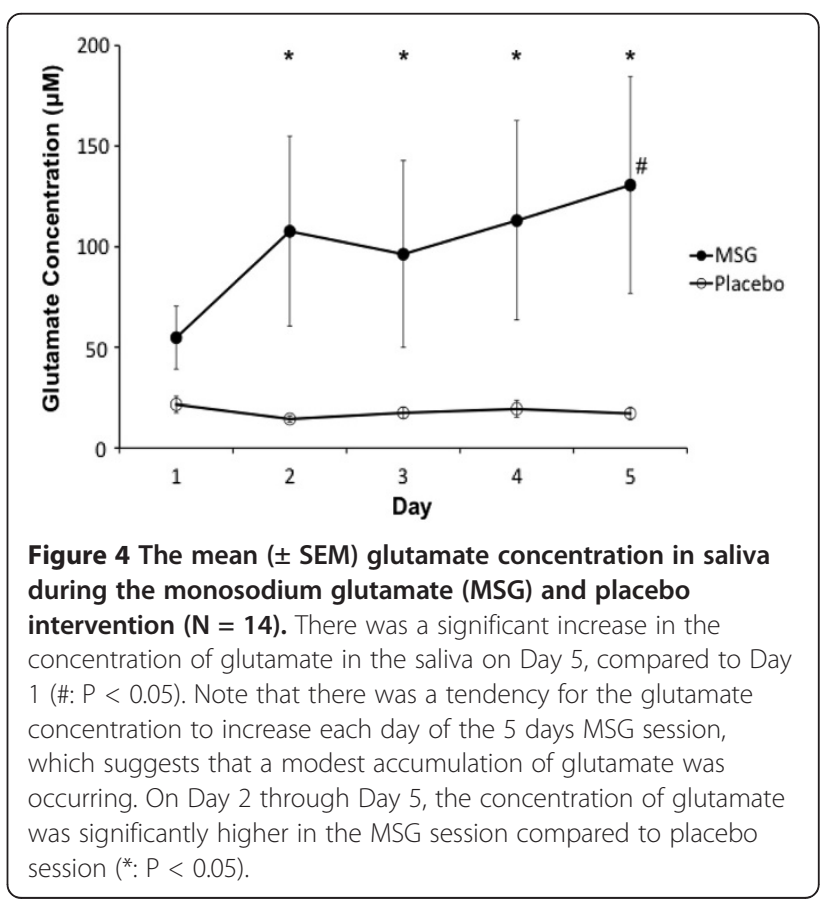




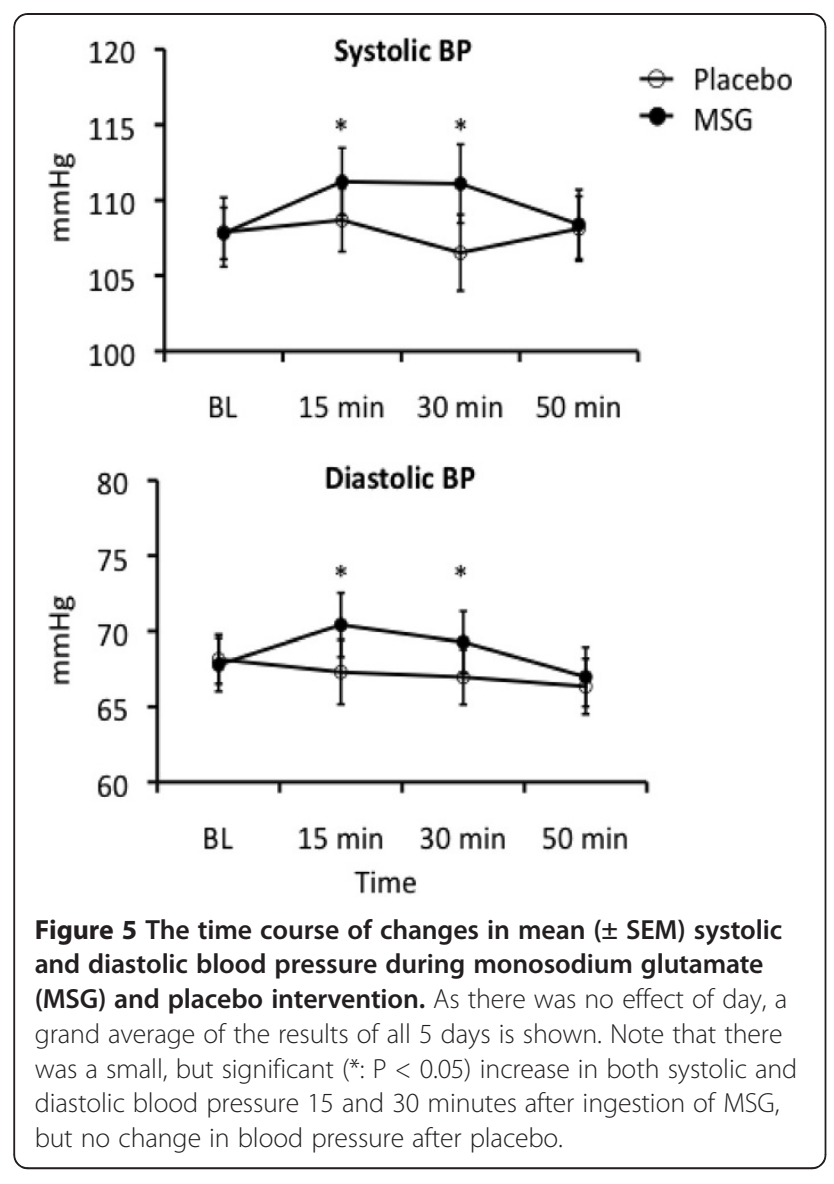

\section{Discussion}

The present study was conducted to probe whether, compared to a single administration, repeated intake of MSG could lead to increased complaints of untoward affects and evidence of accumulation of glutamate. MSG $(150 \mathrm{mg} / \mathrm{kg}$ ) was administered daily for 5 days and pain sensitivity and side effects monitored. Daily intake of this amount of MSG did not result in significant reports of spontaneous pain. However, it did lead to a sustained mechanical sensitization of the masseter muscle that lasted for the duration of MSG administration. This pain sensitizing effect of MSG was not observed in the temporalis muscle, suggesting that the effect was site specific. Daily intake of MSG also caused headaches and dizziness for at least one day out of five in $57 \%$ of subjects. Although tolerance to most side effects of MSG administration appeared to occur, as evidenced by a decrease in the frequency of side effect complaints, the frequency of headache reports remained relatively constant over the 5 days of MSG ingestion. This suggests that tolerance to the headache inducing effects of MSG may not occur. There was also no apparent tolerance to the ability of MSG administration to increased systolic and diastolic blood pressure over the 5 days intervention. Baseline salivary concentrations of glutamate remained constant and were not different between the MSG and placebo sessions. These concentrations are similar to a previous study that reported mean saliva concentrations of glutamate of $18 \pm 1 \mu \mathrm{M}$ in 18 subjects [20]. However, administration of MSG tended to increase salivary glutamate concentration each day, which suggests the potential that accumulation might have been occurring. These findings suggest that daily consumption of elevated amounts of MSG increases craniofacial pain symptoms in otherwise healthy subjects.

There are some differences in the response properties of the masseter and temporalis muscles to glutamate that may underlie the finding of a masseter muscle selective mechanical sensitizing effect of MSG. Elevated concentrations of glutamate induce mechanical sensitization of masticatory muscle nociceptors through activation of peripheral NMDA receptors [15,21]. It has been found that there is a lower expression of NMDA receptors by nociceptors that innervate the temporalis muscle and that the response of temporalis nociceptors to peripheral NMDA receptor activation is less robust than masseter muscle nociceptors [22,23]. Thus, it is possible that there is also a lower expression of peripheral NMDA receptors by nociceptors that innervate the temporalis muscle in healthy human subjects, which results in the temporalis muscle being less sensitive to orally consumed MSG than the masseter muscle [24].

There was a very consistent, albeit relatively small, increase in both systolic and diastolic blood pressure after oral intake of MSG each day. There is recent evidence that increased dietary intake of glutamate over a 5 year period is correlated with an increase in systolic blood pressure, which was more pronounced in women than in men [25]. It is also important to consider whether MSG-induced increases in blood pressure account for the increased incidence of headaches observed in the present as well as previous studies $[13,14]$. Although earlier work suggested that elevated blood pressure causes headaches [26-28], more recent work does not support a strong association. For example, in a large population of Icelandic men and women, it was found that elevated systolic blood pressure was inversely correlated with migraine headache in both men and women [29]. There is also no difference in mean or systolic blood pressure in women with chronic daily headache and women without this condition [30]. These findings suggest that mechanisms other than hypertension may explain MSG-induced headaches.

Glutamate has also been shown to dilate intracranial and extracranial blood vessels through a peripheral NMDA receptor mechanism that involves the release of nitric oxide [31-33]. Many therapeutically employed vasodilators appear to cause headaches as one of their side effects [34]. For example, infusion of nitroglycerin 
reliably induces a headache, which is thought to be due to dilation of extracerebral arteries $[35,36]$. In a recent study in migraine headache patients, infusion of calcitonin gene related peptide (CGRP), a potent neuropeptide vasodilator and migraine headache inducer, was shown to induce vasodilation of arteries only on the side of the migraine headache pain [37]. On the other hand, vasodilation itself is not able to induce pain that occurs only when periovascular nerve endings are sensitized. This shows that a neural factor, i. e. sensitization, seems to be related to chronic MSG administration [38]. We speculate that it could be vasodilation of extracranial blood vessels through peripheral NMDA receptor activation that mediates MSG headaches [39].

Baseline salivary concentrations of glutamate did not increase over the 5 days of MSG intake, however, post MSG glutamate concentrations increased over the 5 day period. Glutamate has an apparent half-life of about 30 min, which suggests that it would be completely cleared from the blood within 4 hrs of ingestion of MSG [14]. Previously, it was reported that a single oral dose of $150 \mathrm{mg} / \mathrm{kg}$ MSG resulted in peak blood glutamate concentrations of a little over $400 \mu \mathrm{M}$, which occurred 30$45 \mathrm{~min}$ after ingestion [14]. This suggests that salivary glutamate concentrations are about $25-50 \%$ of blood concentrations. It has been suggested that as much as $40 \%$ of a $150 \mathrm{mg} / \mathrm{kg}$ oral dose of MSG is removed by and stored in skeletal muscle [14,40]. Increased peak levels in the saliva over the 5 days could reflect saturation of storage sites in the skeletal muscle. Animal research suggests that after systemic administration of MSG (50 mg/kg i.v.) there is a rapid rise in glutamate concentration in the masseter muscle that is associated with significant mechanical sensitization of muscle nociceptors [15]. It is likely that oral MSG consumption increases glutamate concentration in the masseter muscle of human subjects and that this underlies the mechanical sensitization of the masseter muscle seen in the present study.

Although the MSG was dissolved in sugar free lemon soda, which we have previously found masks the taste of MSG [13], the vast majority of subjects correctly identified the substance administered to them when asked at the end of each 5 days session. Considering the significant increase in adverse effects, which occurred during MSG ingestion, this result is understandable. Nevertheless, it does mean that we cannot consider this study truly blind, and this lack of subject blinding might have influenced findings that relied on psychophysical assessments, such as PPT and PPTol, and reporting of side effects. However, it should be noted that even though PPT and PPTol were assessed in two jaw closing muscles, significant differences were only found for the masseter muscle. This suggests that even if subjects thought they knew what they were receiving their responses were not reflective of any systematic bias. Also, the administration of placebo can induce adverse effects such as headache, which complicates clarification of adverse reactions induced by MSG [41]. Though adverse effects of headache in the placebo week also could be observed in the result of the present study, it was seen to a significantly lesser extent than in the MSG week. This may imply that an accumulation of MSG by oral administration could be a factor best avoided by TMD and headache patients. Mechanical sensitization of masseter muscles is one of the typical symptoms of TMD and there is a well-known overlap between painful TMD and headache [42].

\section{Conclusion}

In conclusion, the present study suggests that individuals who consume elevated amounts of MSG in their diet are more likely to suffer from headaches and have masseter muscle sensitivity, two symptoms associated with myofascial TMD. Although far from definitive, the present findings may indicate that there is a link between diet and susceptibility to the development of chronic orofacial pain conditions that include TMD and headache. If future studies can confirm a link, dietary modification could become an important part of treatment aimed at ameliorating symptoms associated with these chronic craniofacial pain conditions.

\section{Competing interest}

The authors declare that there are no conflicts of interest in the publication of this manuscript.

\section{Authors' contributions}

AS participated in collecting data and drafted the manuscript. BEC conceived of the study, and participated in its design and drafted the manuscript. NV and $\mathrm{KU}$ took a part in collecting data and performed the statistical analysis. AMLP carried out the analysis of the saliva samples. PS supervised this study, participated in its design and coordination and helped to draft the manuscript. LBH participated in the design of the study, planned the data collection, performed the statistical analysis, and drafted the manuscript. All authors read and approved the final manuscript.

\section{Acknowledgments}

This study was financially supported by the Danish Dental Association and Danish Medical Research Council.

\section{Author details \\ ${ }^{1}$ Section of Clinical Oral Physiology, Department of Dentistry, Faculty of Health Sciences, Aarhus University, Vennelyst Boulevard 9, Aarhus C 8000 , Denmark. ${ }^{2}$ Faculty of Pharmaceutical Sciences, University of British Columbia, 2405 Wesbrook Mall, Vancouver, BC V6T 1Z3, Canada. '3ection of Oral Medicine, Clinical Oral Physiology, Oral Pathology \& Anatomy, Department of Odontology, Faculty of Health Sciences, University of Copenhagen, Nørre Allé 20, Copenhagen 2200 København N, Denmark. ${ }^{4}$ MindLab, Center for Functionally Integrative Neuroscience, Aarhus University Hospital, Nørrebrogade 44, Aarhus C 8000, Denmark.}

Received: 16 November 2012 Accepted: 19 December 2012 Published: 24 January 2013 


\section{References}

1. Cairns BE (2010) Pathophysiology of TMD pain - basic mechanisms and their implications for pharmacotherapy. J Oral Rehabil 37:391-410. doi:10.1111/j.1365-2842.2010.02074.x

2. LeResche L, Drangsholt M (2008) Epidemiology of orofacial pain: prevalence, incidence, and risk factors. In: Sessle BJ, Lavigne GJ, Lund JP, Dubner R (eds) Orofacial pain: from basic science to clinical management. Quintessence Books, Illinois, pp 13-18

3. Lobbezoo F, Drangsholt MT, Peck C, Sato H, Kopp S, Svensson P (2004) Topical review: new insights into the pathology and diagnosis of disorders of the temporomandibular joint. J Orofac Pain 18:181-191

4. Glaros AG (2008) Temporomandibular disorders and facial pain: a psychophysiological perspective. Appl Psychophysiol Biofeedback 33:161-171. doi:10.1007/s10484-008-9059-9

5. Hutchins MO, Skjonsby HS (1990) Microtrauma to rat superficial masseter muscles following lengthening contractions. J Dent Res 69:1580-1585. doi:10.1177/00220345900690090901

6. Suvinen TI, Reade PC, Kemppainen P, Könönen M, Dworkin SF (2005) Review of aetiological concepts of temporomandibular pain disorders: towards a biopsychosocial model for integration of physical disorder factors with psychological and psychosocial illness impact factors. Eur J Pain 9:613-633. doi:10.1016/j.ejpain.2005.01.012

7. Manfredini D, Lobbezoo F (2010) Relationship between bruxism and temporomandibular disorders: a systematic review of literature from 1998 to 2008. Oral Surg Oral Med Oral Pathol Oral Radiol Endod 109:e26-e50. doi:10.1016/j.tripleo.2010.02.013

8. Svensson P, Jadidi F, Arima T, Baad-Hansen L, Sessle BJ (2008) Relationships between craniofacial pain and bruxism. J Oral Rehabil 35:524-547

9. Raphael KG, Marbach JJ, Touger-Decker R (2002) Dietary fiber intake in patients with myofascial face pain. J Orofac Pain 16:39-47

10. Freeman M (2006) Reconsidering the effects of monosodium glutamate: a literature review. J Am Acad Nurse Pract 18:482-486. doi:10.1111/j.17457599.2006.00160.x

11. Geha RS, Beiser A, Ren C, Patterson R, Greenberger PA, Grammer LC, Ditto AM, Harris KE, Shaughnessy MA, Yarnold PR, Corren J, Saxon A (2000) Review of alleged reaction to monosodium glutamate and outcome of a multicenter double-blind placebo-controlled study. J Nutr 130(4S Suppl):58S-62S

12. Nelson LM, Matkin C, Longstreth WTJ, McGuire V (2000) Population-based case-control study of amyotrophic lateral sclerosis in western Washington State. II. Diet. Am J Epidemiol 151:164-173

13. Baad-Hansen L, Cairns BE, Ernberg M, Svensson P (2010) Effect of systemic monosodium glutamate (MSG) on headache and pericranial muscle sensitivity. Cephalalgia 30:68-76. doi:10.1111/j.1468-2982.2009.01881.x

14. Graham TE, Sgro V, Friars D, Gibala MJ (2000) Glutamate ingestion: the plasma and muscle free amino acid pools of resting humans. Am J Physiol Endocrinol Metab 278:E83-E89

15. Cairns BE, Dong XD, Mann MK, Svensson P, Sessle BJ, Arendt-Nielsen L, McErlane KM (2007) Systemic administration of monosodium glutamate elevates intramuscular glutamate levels and sensitizes rat masseter muscle afferent fibers. Pain 132:33-41. doi:10.1016/j.pain.2007.01.023

16. Castrillon EE, Ernberg M, Cairns BE, Wang K, Sessle BJ, Arendt-Nielsen L, Svensson P (2010) Interstitial glutamate concentration is elevated in the masseter muscle of myofascial temporomandibular disorder patients. J Orofac Pain 24:350-360

17. Pedersen AM, Reibel J, Nauntofte B (1999) Primary Sjögren's syndrome (pSS): subjective symptoms and salivary findings. J Oral Pathol Med 28:303-311. doi:10.1111/j.1600-0714.1999.tb02045.x

18. Bardow A, Pedersen AM, Nauntofte B (2004) Saliva. In: Miles TS, Nauntofte B, Svensson P (eds) Clinical oral physiology. Quintessence Publishing Co. Ltd., Copenhagen, pp 17-51

19. Svensson P, Cairns BE, Wang K, Arendt-Nielsen L (2003) Injection of nerve growth factor into human masseter muscle evokes long-lasting mechanical allodynia and hyperalgesia. Pain 104:241-247. doi:10.1016/S0304-3959(03)00012-5

20. Scinska-Bienkowska A, Wrobel E, Turzynska D, Bidzinski A, Jezewska E, Sienkiewicz-Jarosz H, Golembiowska K, Kostowski W, Kukwa A, Plaznik A, Bienkowski P (2006) Glutamate concentration in whole saliva and taste responses to monosodium glutamate in humans. Nutr Neurosci 9:25-31. doi:10.1080/10284150600621964

21. Gazerani P, Au S, Dong X, Kumar U, Arendt-Nielsen L, Cairns BE (2010) Botulinum neurotoxin type $A$ (BoNTA) decreases the mechanical sensitivity of nociceptors and inhibits neurogenic vasodilation in a craniofacial muscle targeted for migraine prophylaxis. Pain 151:606-616. doi:10.1016/j. pain.2010.07.029

22. Dong XD, Mann M, Kumar U, Svensson P, Arendt-Nielsen L, Hu JW, Sessle BJ, Cairns BE (2007) Sex-related differences in NMDA-evoked rat masseter muscle afferent discharge result from estrogen-mediated modulation of peripheral NMDA receptor activity. Neuroscience 146:822-832. doi:10.1016/j. neuroscience.2007.01.051

23. Dong XD, Mann MK, Sessle BJ, Arendt-Nielsen L, Svensson P, Cairns BE (2006) Sensitivity of rat temporalis muscle afferent fibers to peripheral $\mathrm{N}$ methyl-D-aspartate receptor activation. Neuroscience 141:939-945. doi:10.1016/j.neuroscience.2006.04.024

24. Castrillon EE, Cairns BE, Wang K, Arendt-Nielsen L, Svensson P (2012) Comparison of glutamate-evoked pain between the temporalis and masseter muscles in men and women. Pain 153:823-829. doi:10.1016/j. pain.2012.01.003

25. Shi Z, Yuan B, Taylor AW, Dai Y, Pan X, Gill TK, Wittert GA (2011) Monosodium glutamate is related to a higher increase in blood pressure over 5 years: findings from the Jiangsu Nutrition Study of Chinese adults. $J$ Hypertens 29:846-853. doi:10.1097/HJH.0b013e328344da8e

26. Bulpitt CJ, Dollery CT (1976) Change in symptoms of hypertensive patients after referral to hospital clinic. Br Heart Journal 38:121-128. doi:10.1136/ hrt.38.2.121

27. Cooper WD, Glover DR, Hormbrey JM, Kimber GR (1989) Headache and blood pressure: evidence of a close relationship. J Human Hypertension 3:41-44

28. Waters WE (1971) Headache and blood pressure in the community. Br Med J 1:142-143. doi:10.1136/bmj.1.5741.142

29. Gudmundsson LS, Thorgeirsson G, Sigfusson N, Sigvaldason H, Johannsson M (2006) Migraine patients have lower systolic but higher diastolic blood pressure compared with controls in a population-based study of 21537 subjects. The Reykjavik Study Cephalalgia 26:436-444. doi:10.1111/j.14682982.2005.01057.x

30. Benseñor IJM, Lotufo PA, Mion D Jr, Martins MA (2002) Blood pressure behaviour in chronic daily headache. Cephalalgia 22:190-194. doi:10.1046/ j.1468-2982.2002.00340.x

31. Busija DW, Leffler CW (1989) Dilator effects of amino acid neurotransmitters on piglet pial arterioles. Am J Physiol 257:H1200-H1203

32. Cairns BE, Gambarota G, Dunning PS, Mulkern RV, Berde CB (2003) Activation of peripheral excitatory amino acid receptors decreases the duration of local anesthesia. Anesthesiology 98:521-529. doi:10.1097/ 00000542-200302000-00035

33. Fergus A, Lee KS (1997) Regulation of cerebral microvessels by glutamatergic mechanisms. Brain Res 754:35-45. doi:10.1016/S0006-8993(97)00040-1

34. Bagdy G, Riba P, Kecskeméti V, Chase D, Juhász G (2010) Headache-type adverse effects of NO donors: vasodilation and beyond. Br J Pharmacol 160:20-35. doi:10.1111/j.1476-5381.2010.00643.x

35. Ashina M, Tfelt-Hansen P, Dalgaard P, Olesen J (2011) Lack of correlation between vasodilatation and pharmacologically induced immediate headache in healthy subjects. Cephalalgia 31:683-690. doi:10.1177/ 0333102410394672

36. Hansen JM, Pedersen D, Larsen VA, Sánchez-del-Rio M, Alvarez Linera JR, Olesen J, Ashina M (2007) Magnetic resonance angiography shows dilatation of the middle cerebral artery after infusion of glyceryl trinitrate in healthy volunteers. Cephalalgia 27:118-127. doi:10.1111/j.14682982.2006.01257.x

37. Asghar MS, Hansen AE, Amin FM, van der Geest RJ, Pv K, Larsson HB, Olesen J, Ashina M (2011) Evidence for a vascular factor in migraine. Ann Neurol 69:635-645. doi:10.1002/ana.22292

38. Burstein R, Jakubowski M, Rauch SD (2011) The science of migraine. J Vestib Res 21:305-314. doi:10.3233/NES-2012-0433

39. Chan KY, Gupta S, de Vries R, Danser AH, Villalón CM, Muñoz-Islas E, Maassenvandenbrink A (2010) Effects of ionotropic glutamate receptor antagonists on rat dural artery diameter in an intravital microscopy model. Br J Pharmacol 160:1316-1325. doi:10.1111/j.1476-5381.2010.00733.x

40. Rutten EP, Engelen MP, Gosker H, Bast A, Cosemans K, Vissers YL, Wouters EF, Deutz NE, Schols AM (2008) Metabolic and functional effects of glutamate intake in patients with chronic obstructive pulmonary disease (COPD). Clin Nutr 27:408-415. doi:10.1016/j. clnu.2008.03.00

41. Yang WH, Drouin MA, Herbert M, Mao Y, Karsh J (1997) The monosodium glutamate symptom complex: assessment in a double-blind, placebo- 
controlled, randomized study. J Allergy Clin Immunol 99:757-762. doi:10.1016/50091-6749(97)80008-5

42. Anderson GC, John MT, Ohrbach R, Nixdorf DR, Schiffman EL, Truelove ES, List T (2011) Influence of headache frequency on clinical signs and symptoms of TMD in subjects with temple headache and TMD pain. Pain 152:765-771. doi:10.1016/j.pain.2010.11.007

doi:10.1186/1129-2377-14-2

Cite this article as: Shimada et al:: Headache and mechanical sensitization of human pericranial muscles after repeated intake of monosodium glutamate (MSG). The Journal of Headache and Pain 2013 $14: 2$

Submit your manuscript to a SpringerOpen ${ }^{\circ}$ journal and benefit from:

- Convenient online submission

- Rigorous peer review

- Immediate publication on acceptance

- Open access: articles freely available online

- High visibility within the field

- Retaining the copyright to your article 